\title{
Cost Calculation for a Flash Glucose Monitoring System for Adults with Type 2 Diabetes Mellitus Using Intensive Insulin - a UK Perspective
}

\author{
Richard Hellmund, ${ }^{1}$ Raimund Weitgasser ${ }^{2,3}$ and Deirdre Blissett ${ }^{4}$
}

1. Abbott Diabetes Care, Alameda, CA, US; 2. Abteilung für Innere Medizin, Privatklinik Wehrle-Diakonissen, Salzburg, Austria;

3. Paracelsus Medizinische Privatuniversität Salzburg, Austria; 4. MedTech Economics Ltd, Winchester, UK

\begin{abstract}
A ims: Estimate the costs associated with flash glucose monitoring as a replacement for routine self-monitoring of blood glucose (SMBG) in patients with type 2 diabetes mellitus (T2DM) using intensive insulin, from a UK National Health service (NHS) perspective. Methods: The base-case cost calculation used the frequency of SMBG and healthcare resource use observed in the REPLACE trial. Scenario analyses considered SMBG at the flash monitoring frequencies observed in the REPLACE trial (8.3 tests per day) and a real-world analysis (16 tests per day). Results: Compared with 3 SMBG tests per day, flash monitoring would cost an additional $£ 585$ per patient per year, offset by a $£ 776$ reduction in healthcare resource use, based on reductions in emergency room visits (41\%), ambulance call-outs (66\%) and hospital admissions (77\%) observed in the REPLACE trial. Per patient, the estimated total annual cost for flash monitoring was $f 191$ (13.4\%) lower than for SMBG. In the scenarios based on acquisition cost alone, flash monitoring was cost-neutral versus 8.3 SMBG tests per day (5\% decrease) and cost-saving at higher testing frequencies. Conclusion: From a UK NHS perspective, for patients with T2DM using intensive insulin, flash monitoring is potentially cost-saving compared with routine SMBG irrespective of testing frequency.
\end{abstract}

\section{Keywords}

Diabetes, flash, monitoring, cost, calculation, hypoglycaemia

Disclosure: Richard Hellmund is a full-time employee of Abbott Diabetes Care and is a stock holder. Raimund Weitgasser serves as a consultant and has received lecture fees from Abbott Diabetes Care. Deirdre Blissett has been paid to act as an independent health economic consultant on behalf of Abbott Diabetes Care.

Acknowledgements: Medical writing support was provided by Sophie Shina of Oxford PharmaGenesis, UK, with funding from Abbott Diabetes Care.

Compliance with Ethics: This study involves a cost analysis and did not involve any studies with human or animal subjects performed by any of the authors.

Authorship: All named authors meet the International Committee of Medical Journal Editors (ICMJE) criteria for authorship of this manuscript, take responsibility for the integrity of the work as a whole, and have given final approval to the version to be published.

open Access: This article is published under the Creative Commons Attribution Noncommercial License, which permits any non-commercial use, distribution, adaptation and reproduction provided the original author(s) and source are given appropriate credit. @) The Authors 2018. Received: 11 April 2018

Accepted: 12 July 2018

Citation: European Endocrinology, 2018;14(2):86-92 Corresponding author: Richard Hellmund, Abbott Diabetes Care, 1420 Harbor Bay Parkway, Alameda, CA 94502, US. E: richard.hellmund@abbott.com

Funding: This work was supported

by Abbott Diabetes Care.
Unmet needs for people with type 2 diabetes mellitus using intensive insulin

Despite advances in diabetes management, many people with type 2 diabetes mellitus (T2DM) fail to achieve optimal glycaemic control, as demonstrated in a 2016-2017 audit of England and Wales, in which only $67 \%$ of people with T2DM achieved target glycated haemoglobin (HDA1C) levels $(\leq 58 \mathrm{mmol} / \mathrm{mol}) .{ }^{1}$ When glucose levels can no longer be regulated through lifestyle management and non-insulin pharmacological therapy, people with T2DM may need to use insulin. Insulin is an effective treatment for diabetes, but it is also the most common cause of hypoglycaemia, which in turn is associated with adverse clinical outcomes including increased risk of cardiovascular events and reduced survival. ${ }^{2-5}$ It has been estimated that people with T2DM who manage their diabetes using insulin and routine self-monitoring of blood glucose (SMBG) experience a mean of 1.05 severe hypoglycaemic events per year. ${ }^{4}$

\section{Economic burden of T2DM}

T2DM places a large financial burden on healthcare systems due to the expense of managing complications, as well as the costs associated with glucose monitoring, insulin and essential medicines such as agents that lower blood pressure and lipid levels. ${ }^{6}$ The International Diabetes Federation estimated in 2015 that 1 in 11 adults have diabetes of any type, and that in high-income countries, up to $91 \%$ of adults with the disease have T2DM. ${ }^{7}$ T2DM has a significant financial impact as a result of acute hypoglycaemic events associated with insulin use, sustained periods of hyperglycaemia and the long-term complications of suboptimal glucose control. ${ }^{8-10} \mathrm{~A}$ cost analysis using data from population-based studies in southern Germany reported that patients with T2DM $(\mathrm{n}=880)$ had 1.81 (95\% confidence interval [Cl], 1.56-2.11) times higher direct $(€ 3,352$ versus $€ 1,849)$ annual costs, and $2.07(95 \% \mathrm{Cl}, 1.51-2.84)$ times higher indirect $(€ 4,103$ versus $€ 1,981)$ annual costs than people without diabetes. ${ }^{11}$ In addition, patients treated with insulin had $3.98(95 \% \mathrm{Cl}, 2.74-5.77)$ times higher direct costs, compared with individuals without diabetes. ${ }^{11}$

In 2010-2011, the total annual cost of T2DM was estimated to be $f 21.8$ billion in the UK. This comprised $£ 8.8$ billion in direct costs, of which, approximately $80 \%$ was owing to complications, and $£ 13$ billion in indirect costs owing to death, sickness, presenteeism and caregiver burden. ${ }^{10}$ The cost to the UK National Health Service (NHS) per year for severe hypoglycaemia

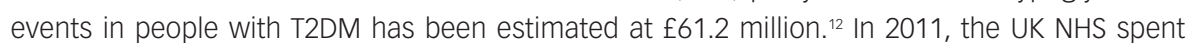
f158 million on SMBG, which accounted for $21 \%$ of prescription costs associated with diabetes. ${ }^{13}$ 
With increasing levels of obesity and physical inactivity, the prevalence of T2DM is rising, and thus the burden of disease is expected to increase over time. ${ }^{8}$

\section{Glucose monitoring for people with type 2 diabetes mellitus using intensive insulin Self-monitoring of blood glucose}

Glucose monitoring is an essential process that helps people with T2DM using intensive insulin to self-manage their disease and maintain their glucose levels within the range recommended to reduce the risk of acute complications, including hypoglycaemia, and poor long-term outcomes. The current standard of care is SMBG using blood glucose meters, lancets and test strips..$^{14}$ The 2015 National Institute for Health and Care Excellence (NICE) guideline for the management of adults with T2DM recommends that SMBG should be offered to those using insulin, but does not suggest an optimal frequency of testing. ${ }^{15}$ By contrast, the 2017 American Diabetes Association (ADA) standards of care specify that patients using intensive insulin regimens should test 6-10 times (or more) daily, ${ }^{16}$ and the European Consensus Statement recommends 4-8 tests per day for these patients. ${ }^{17}$ Evidence suggests that many patients using intensive insulin do not test 4 or more times per day and a significant number may test much less often.

In a UK study including 946 patients with T1DM and T2DM using intensive insulin, the mean number of test strips per day was $2.68 .{ }^{18}$ This implies that many of these patients were testing less than 2.68 times each day, particularly because prescription record studies tend to over-estimate actual utilisation, and the mean value may be inflated by a small proportion of patients who test very frequently. Other studies also suggest a low rate of testing in similar populations: in the US and Canada (mean of 2.6 and 3.6 tests per day respectively), in Argentina (mean of 3.3 tests per day), in China (mean of 4.0 tests per week) ${ }^{19-22}$ and in the randomised clinical trial REPLACE (mean [ \pm SD] of 3.8 [1.4] tests per day) ${ }^{23}$ These studies suggest that a significant proportion of patients with T2DM using intensive insulin may not conduct SMBG as often as they should to adequately manage their condition. Various reasons for patients not using SMBG frequently enough have been identified, including the inconvenience and invasiveness of the test procedure, pain and social stigma. ${ }^{24,25}$

As indicated by the guidelines, some patients with T2DM using intensive insulin may require 8 or more glucose tests per day, for example before each meal and before driving, exercise or going to bed. This frequency of testing may be appropriate for patients who experience a high level of glucose variability over the 24-hour day or who have a history of severe hypoglycaemia.

Insufficient adherence to SMBG testing is associated with increased HDA1C levels and inadequate glycaemic control in people with T2DM, which may lead to poor long-term outcomes including unplanned primary care visits, admission to hospital due to hypoglycaemia, and the development and exacerbation of comorbidities. ${ }^{26-28}$ Therefore, ensuring adequate and affordable glucose monitoring for people with T2DM using intensive insulin is an important goal. A significant proportion of these patients may not be able to test frequently enough owing to the limitations of SMBG.

\section{Flash glucose monitoring system}

The Freestyle Libre'T system (Abbott Diabetes Care, Witney, UK) is a minimally invasive sensor-based flash glucose monitoring system, indicated for use in adults and children with diabetes mellitus, which
Table 1: Baseline patient characteristics in the REPLACE trial (full analysis set)

\begin{tabular}{|c|c|c|}
\hline & $\begin{array}{l}\text { Flash monitoring } \\
\text { system } \\
(n=149)\end{array}$ & $\begin{array}{l}\text { SMBG } \\
(n=75)\end{array}$ \\
\hline $\begin{array}{l}\text { MDI (pen or syringe)/CSII (insulin } \\
\text { pump), \% }\end{array}$ & $94.6 / 5.4$ & $94.7 / 5.3$ \\
\hline Mean age, years (SD) & $59.0(9.9)$ & $59.5(11.0)$ \\
\hline $\begin{array}{l}\text { Mean } \mathrm{HbA} 1 \mathrm{c}, \%(\mathrm{SD}) \\
\text { Mean } \mathrm{HbA} 1 \mathrm{c}, \mathrm{mmol} / \mathrm{mol}(\mathrm{SD})\end{array}$ & $\begin{array}{l}8.65(1.01) \\
71.0(11.1)\end{array}$ & $\begin{array}{l}8.75(0.98) \\
72.1(10.7)\end{array}$ \\
\hline Mean duration of diabetes, years (SD) & $17(8)$ & $18(8)$ \\
\hline Mean duration of insulin, years (SD) & $9(6)$ & $10(7)$ \\
\hline $\begin{array}{l}\text { Mean total daily dose of insulin, } \\
\text { units (SD) } \\
\text { Basal } \\
\text { Bolus } \\
\text { CSII }\end{array}$ & $\begin{array}{l}40.4(22.6) \\
50.5(32.5) \\
76.9(49.6)\end{array}$ & $\begin{array}{l}42.3(25.1) \\
54.8(32.7) \\
82.6(37.0)\end{array}$ \\
\hline $\begin{array}{l}\text { Patients with concomitant disease or } \\
\text { history of disease, }{ }^{\text {a } \%}\end{array}$ & 63.1 & 66.7 \\
\hline $\begin{array}{l}\text { Mean frequency of SMBG, tests per } \\
\text { day (SD) }\end{array}$ & $3.8(1.4)$ & $3.9(1.5)$ \\
\hline
\end{tabular}

${ }^{a}$ Documented concomitant diseases were neuropathy, retinopathy, cardiovascular complications, depression, renal complications, cataract, macular oedema and foot ulcer complications. CSII = continuous subcutaneous insulin infusion; HDA1C = glycated haemoglobin; $M D I=$ multiple daily injection therapy; $S D=$ standard deviation; $S M B G=$ self-monitoring of blood glucose.

measures glucose levels in a patient's interstitial fluid. Data are wirelessly transferred from a sensor (which is applied to the back of the upper arm and lasts for up to 14 days) to a handheld reader. ${ }^{29}$ The flash monitoring system is factory-calibrated and does not require calibration using SMBG. People using the flash monitoring system need to use SMBG to check readings in three circumstances: 1) during times of rapidly changing glucose levels; 2) to confirm hypoglycaemia or impending hypoglycaemia; and 3) if their symptoms do not correlate with the flash monitoring system reading.

The clinical benefit of the flash monitoring system for people with T2DM using intensive insulin has been demonstrated in the randomised clinical trial REPLACE. ${ }^{23}$ The REPLACE trial was designed to reflect realworld clinical practice according to local practices in the centres that took part in the trial, to ensure the relevance of the findings. There were no protocol-mandated insulin regimen adjustments, and investigators could make treatment decisions as they saw fit. In total, 302 people with T2DM using insulin were enrolled at 26 sites across Germany, France and the UK, with 224 randomised to flash monitoring $(n=149)$ or SMBG $(n=75)$.

At baseline, the mean $( \pm$ SD) age in the overall trial population was 59.2 (10.3) years, similar to the age distribution of patients with T2DM identified in the 2016-2017 England and Wales audit. ${ }^{1}$ The proportion of participants who had concomitant disease or a previous history of other disease was 64.3\% (Table 1). Glucose control was poor, despite the use of 3.7 SMBG tests per day on average at baseline. Mean $( \pm$ SD) HbA1C at baseline was $8.7 \%(1.0 \%)$, corresponding to $71.4 \mathrm{mmol} / \mathrm{mol}$, and participants experienced a mean of 1.19 hours per day of hypoglycaemia (glucose $<3.9 \mathrm{mmol} / \mathrm{L}$ [70 mg/dL]) during the 2-week baseline period. Mean time in range $(3.9-10.0 \mathrm{mmol} / \mathrm{L}$ [70-180 mg/dL]) was low, at 13.7 hours per day. The mean $( \pm$ SD) total daily dose of basal insulin, bolus insulin and continuous subcutaneous insulin infusion was 41.1 (23.4), 51.9 (32.6) and 78.4 (44.7) units, respectively.23 
Over the 6-month comparative phase of the REPLACE trial, reductions in $\mathrm{HbA} 1 \mathrm{C}$ were similar in both groups, although, a pre-specified analysis of a subgroup of participants aged $<65$ years $(n=142)$ showed a statistically significant reduction in $\mathrm{HbA} 1 \mathrm{C}$ in favour of the flash monitoring system group from baseline to 6 months (adjusted mean difference, $-0.33 \%$ $[95 \% \mathrm{Cl},-0.62,-0.03] ; \mathrm{p}=0.0301)$. Flash monitoring users experienced substantial decreases in the mean number and duration of daytime and nocturnal hypoglycaemia compared with routine SMBG users, with no associated increases in mean $\mathrm{HbA} 1 \mathrm{C}$ and no change in the total daily dose of insulin. For example, there was a $43 \%$ reduction in number of hours in hypoglycaemia (glucose $<3.9 \mathrm{mmol} / \mathrm{L}$ [70 mg/dL]) in the flash monitoring system group compared with the SMBG group; for the lower glucose threshold of $2.5 \mathrm{mmol} / \mathrm{L}(45 \mathrm{mg} / \mathrm{dL})$ the reduction was $64 \%$ in favour of flash monitoring.

Participants using flash monitoring scanned a mean ( \pm SD, median) of 8.3 $(4.4,6.8)$ times per day during the 6-month treatment period. After starting to use flash monitoring, participants rapidly reduced the number of SMBG tests performed, from a mean (median) of 3.8 (3.8) at baseline to 0.5 (0.1) times per day during the first 2 weeks of usage. They continued at a similar rate during the study, testing a mean (median) of $0.3(0.1)$ times per day overall during the 6-month treatment period. Compared with SMBG, use of flash monitoring was associated with higher treatment satisfaction. There were no serious adverse events related to flash monitoring. Six participants (4\%) who used flash monitoring reported nine device-related adverse events that were primarily treated with topical preparations. All device-related adverse events were resolved by the end of the study. ${ }^{23}$

Substantially lower all-cause healthcare resource use was observed for the flash monitoring participants. Resource use was self-reported in event diaries, which were brought to clinic visits. ${ }^{23,30}$ The specific reason for the difference in resource use is unknown, although it is plausible that this was related to the combined reduction in $\mathrm{HbA} 1 \mathrm{C}$ and hypoglycaemia in participants aged $<65$ years who used flash monitoring, alongside the even greater reduction in hypoglycaemia in participants aged $\geq 65$ years who used flash monitoring. In support of this, Haak et al. (2017) suggested that older patients using flash monitoring in the REPLACE trial prioritised hypoglycaemic reduction over a more indiscriminate approach to glucose control. ${ }^{23}$

Patients who were allocated to use flash monitoring were eligible to continue into an open-label extension where they used the flash monitoring system for an additional 6 months. ${ }^{31}$ Over the entire 12-month period, flash monitoring was associated with a substantial and sustained reduction in hypoglycaemia, and flash monitoring safely and effectively replaced SMBG. The flash monitoring system for patients with T2DM using intensive insulin is currently reimbursed nationally or regionally in 11 European countries, including France, Germany, Italy, the UK and Japan. It has also been approved for reimbursement for patients with T2DM using insulin by some private payers in Canada and for US Medicare patient.

A Medtech Innovation Briefing produced by NICE in 2017 stated that flash monitoring "is intended to be used as an alternative to routine blood glucose monitoring for people aged $>4$ years with T1 orT2DM, who have multiple daily injections of insulin or who use insulin pumps and are self-managing their diabetes."

\section{Objective}

The objective of this cost calculation was to estimate the costs associated with the flash monitoring system as a replacement for routine SMBG for people with T2DM using intensive insulin. The calculation was developed from a UK NHS perspective using annual costs of glucose monitoring and all-cause healthcare resource use, with inputs obtained from the results of the REPLACE trial.

\section{Materials and methods}

For patients with T2DM who are receiving intensive insulin, the major costs to a healthcare system are expected to be those arising from glucose monitoring and resource utilisation associated with the management of comorbidities and diabetes complications.

\section{Base case - routine SMBG at the frequency observed in the REPLACE trial Glucose monitoring}

Costs of glucose monitoring include the acquisition costs of the flash monitoring system sensors (£35.00 per sensor as listed by the UK NHS in 2017) and the costs of lancets (£0.04 per lancet) and test strips ( $\left(0.29\right.$ per test strip). ${ }^{32}$ SMBG consumable costs were based on the mean weighted prices for the top 10 suppliers in the UK market, using IMS Health data. For this calculation the flash monitoring reader is assumed to be provided at no cost, because it is not listed by the UK NHS. Sensor duration is defined in the product label as up to 14 days. The calculation has assumed a 14-day duration for each sensor, which is supported by the median sensor duration of 13.8 days observed in the REPLACE trial, ${ }^{23}$ and by realworld evidence based on over 50,000 readers that showed a median sensor duration of 13.92 days (interquartile range, 13.61-13.95). ${ }^{33}$ SMBG use was based on the testing frequency observed in the REPLACE trial. Routine SMBG users carried out a mean of 3.0 SMBG tests per day during the 6-month comparative phase, and flash monitoring users conducted a mean of 0.3 tests per day over the same period. ${ }^{34}$

\section{Healthcare resource use}

All-cause healthcare resource use was recorded in the REPLACE trial, including emergency room (ER) visits, ambulance call-outs and hospital admissions. It is summarised in Figure 1 for the overall population and for subgroups based on age $<65$ years and age $\geq 65$ years. The event rates for the overall population were incorporated into the cost calculation by doubling the rate observed over the 6-month treatment period to obtain an annual value. Healthcare resource use costs were taken from UK NHS reference costs for the 2016-2017 financial year. ${ }^{35}$ All-cause resource use, rather than diabetes-specific resource use, is relevant for people with T2DM using intensive insulin because they tend to be older than the average person with diabetes and often have a high burden of long-term complications and comorbidities. ${ }^{36}$ All-cause resource use is appropriate in cases such as this, when it is not possible to objectively assess whether or not events are disease-specific. ${ }^{36-39}$

\section{Scenario analyses}

To achieve optimal glucose control, people with T2DM using intensive insulin may require more than the 3 SMBG tests per day used in the base case. In the first scenario, a rate of 8.3 tests per day was used to match the mean scanning frequency observed in the REPLACE study by people using flash monitoring; ${ }^{23}$ at this scanning rate, participants achieved important clinical benefits compared with SMBG at a frequency of 3 tests per day. A second scenario used a similar approach, based on the rate of 16 tests per day that was observed in a database including over 50,000 flash monitoring sensors in real-world use..$^{40}$ Because this is an anonymised database, it is unknown which patients had T2DM and which had T1DM. There are also no data available to show how 
Figure 1: All-cause healthcare resource use observed in the 6-month treatment period of the REPLACE trial

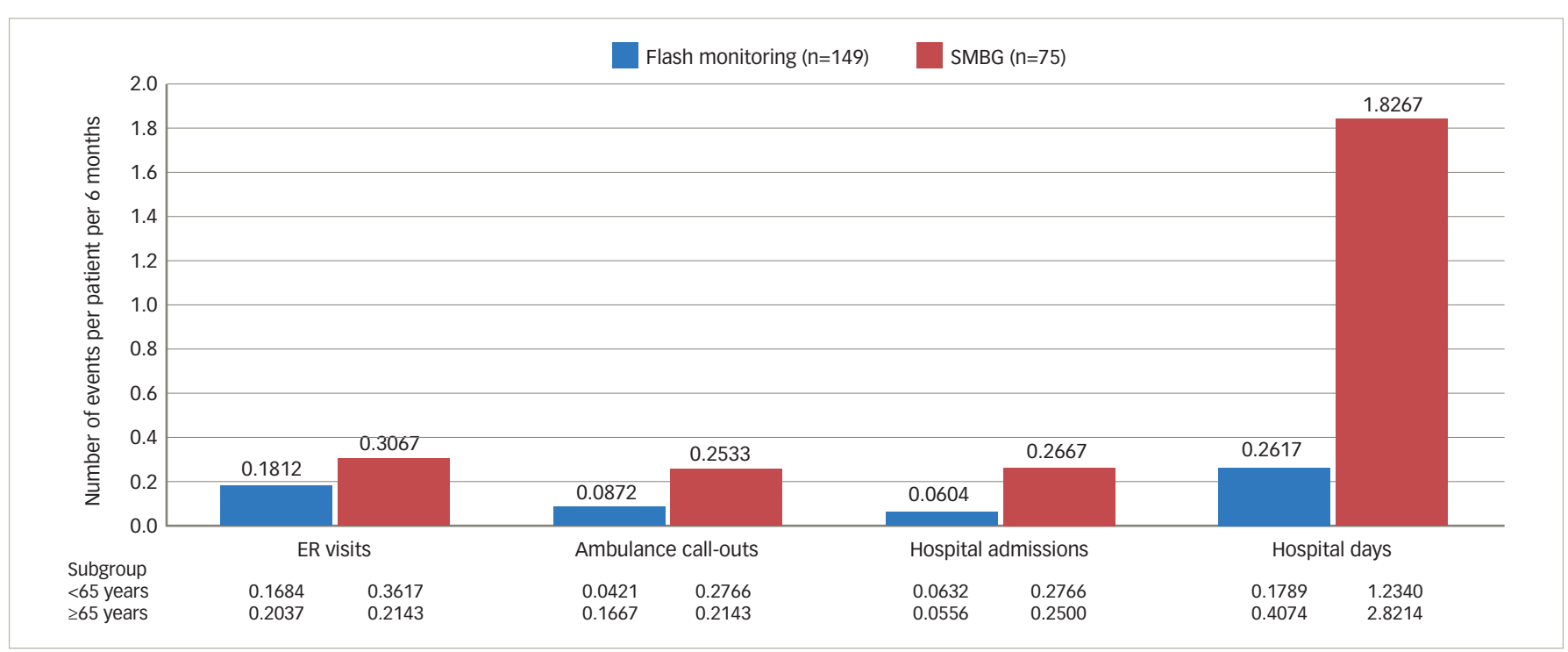

$E R$ = emergency room; SMBG = self-monitoring of blood glucose

this population compared with the REPLACE study participants for other measures.

Resource use costs were not included in these scenarios because resource use at SMBG frequencies of 8.3 and 16 tests per day may be different from that observed for routine SMBG in the REPLACE trial.

\section{Results}

\section{Base case calculation Glucose monitoring}

Using the frequency of SMBG observed in the REPLACE trial, the annual per-patient cost of glucose monitoring with routine SMBG was estimated to be $£ 361$, based on three lancets and test strips per day. The annual per-patient cost of flash monitoring is 1910 : when this was combined with SMBG costs of $£ 36$ (based on 0.3 lancets and test strips per day), the additional annual cost for the flash monitoring system compared with a routine SMBG user was estimated to be $f 585$ (Table 2).

\section{Healthcare resource use}

In the REPLACE trial, flash monitoring was associated with a substantial reduction in all-cause healthcare resource use compared with SMBG. Over the 6-month comparative period, fewer ER visits (41\%), ambulance call-outs (66\%) and hospital admissions (77\%) were observed for flash monitoring participants (Figure 1). In both age subgroups ( $<65$ years and $\geq 65$ years), the pattern of resource use was the same as for the overall population, with resource use lower in the flash monitoring group than in the SMBG group, particularly in regard to hospital admissions and days spent in hospital. This demonstrates that even though the clinical benefit for flash monitoring users is different for patients aged $<65$ years than for those aged $\geq 65$ years, ${ }^{23}$ the requirement for healthcare resources may be reduced in both age subgroups. The mean annual per-patient cost of healthcare resource use was estimated to be $f 289$ for a patient using flash monitoring compared with $\mathrm{£} 1,065$ for a patient using SMBG, a $f 776$ reduction per patient per year (Table 3).

\section{Aggregate costs of glucose monitoring and all-cause healthcare resource use}

The total annual cost for the flash monitoring system, including healthcare resource use, is estimated to be $£ 1,235$ per patient, compared with $£ 1,426$ for a patient using routine SMBG. This represents a reduction of $£ 191$ per patient per year for the flash monitoring system compared with SMBG, a 13.4\% decrease in cost (Figure 2).

\section{Scenario analyses}

Each additional daily SMBG test adds $£ 120$ per patient per year to the cost of glucose monitoring, whereas the acquisition cost of flash monitoring is the same irrespective of testing frequency. For the first scenario, monitoring 8.3 times per day using SMBG would cost a total of $£ 1,000$ per patient per year, $£ 54$ per patient higher than the estimated annual cost of flash monitoring (Table 2). When monitoring more than 8.3 times per day, the annual cost of flash monitoring will be less than for SMBG. This is demonstrated by the second scenario, where SMBG at 16 tests each day costs $£ 1,927$ per patient per year, compared with flash monitoring at $£ 946$.

\section{Discussion}

Glucose monitoring guidelines indicate that patients with T2DM using intensive insulin need to test regularly to maintain glycaemic control, avoid severe hypoglycaemia and reduce the risk of complications. Although the guidelines differ as to the number of tests required, 4 tests per day could be considered a lower limit to safely and effectively adjust insulin doses, ${ }^{17,23}$ although some patients may require 8 tests or more per day. ${ }^{16,17}$ More frequent testing may be especially important for certain patient groups such as those with high glucose variability or who have a history of severe hypoglycaemia.

Evidence from five countries suggests that many of these patients do not test 4 or more times a day, even though they are using intensive insulin. ${ }^{18-22}$ These studies suggest the average patient with T2DM using intensive insulin may use SMBG somewhere between 2.6-3.6 times per day, which implies there will be many patients testing less than four times per day. The actual deficit in glucose monitoring may be higher than suggested by these studies because they are based on prescription record data, which tends to over-estimate actual utilisation of SMBG.

The flash monitoring system may enable an increase in glucose testing frequency for T2DM patients who are using intensive insulin but who are 
Table 2: Estimated annual glucose monitoring costs and resource use for a patient using the flash glucose monitoring system and for those using SMBG

\begin{tabular}{|c|c|c|c|}
\hline & Base case & \multicolumn{2}{|l|}{ Scenario analysis } \\
\hline $\operatorname{SMBG}(£)$ & $\begin{array}{l}3 \text { SMBG tests } \\
\text { per day }\end{array}$ & $\begin{array}{l}\text { 8.3 SMBG tests } \\
\text { per day }\end{array}$ & $\begin{array}{l}16 \text { SMBG tests } \\
\text { per day }\end{array}$ \\
\hline Cost per lancet & $£ 0.04$ & $£ 0.04$ & $£ 0.04$ \\
\hline Cost per test strip & f0.29 & $£ 0.29$ & $£ 0.29$ \\
\hline Cost of lancet and test strip & $£ 0.33$ & $£ 0.33$ & $£ 0.33$ \\
\hline \multicolumn{4}{|l|}{ Flash monitoring system ( $\mathrm{f}$ ) } \\
\hline Cost per reader & 0 & 0 & 0 \\
\hline Cost per sensor & $£ 35.00$ & $£ 35.00$ & $£ 35.00$ \\
\hline Cost of reader and sensor, PPPY & $£ 910.00$ & $£ 910.00$ & $£ 910.00$ \\
\hline Cost of lancet and test strip for flash monitoring system users, PPPYc & $£ 36.14$ & $£ 36.14$ & $£ 36.14$ \\
\hline Cost saving using flash monitoring vs SMBG, PPPY (£) & $-£ 584.79$ & $£ 53.60$ & £981.07 \\
\hline Estimated cost of resource use for routine SMBG users, PPPY (see Table 3) & $£ 1,064.53$ & \multirow{5}{*}{\multicolumn{2}{|c|}{ Excluded from scenario analysis ${ }^{d}$}} \\
\hline Overall costs for SMBG users (including resource use), PPPY & $£ 1,425.88$ & & \\
\hline Estimated cost of resource use for flash monitoring system users, PPPY (see Table 3) & $£ 288.96$ & & \\
\hline Overall costs for flash monitoring system users (including resource use), PPPY & $£ 1,235.10$ & & \\
\hline Overall cost saving using flash monitoring versus SMBG (including resource use), PPPY (f) & $£ 190.78$ & & \\
\hline
\end{tabular}

${ }^{a}$ ASsumption: use of 3 SMBG tests per day in the REPLACE trial (base case), or either 8.3 or 16 SMBG tests per day (scenario analysis). ${ }^{b}$ ASSumption: use of 26 sensors per year (sensor life is up to 14 days). ' Assumption: use of 0.3 SMBG tests per day observed in the REPLACE trial. dResource use costs were not included in these scenario analyses because resource use at these SMBG frequencies may be different from that observed in the REPLACE study. PPPY = per patient per year; SMBG = self-monitoring of blood glucose.

Table 3: Annual all-cause healthcare resource use costs calculated from data observed in the REPLACE trial

\begin{tabular}{|c|c|}
\hline \multicolumn{2}{|l|}{ ER visits } \\
\hline Cost per ER visit, UK NHS reference for 2016-201735 a & £148.00 \\
\hline ER visits, PPPY: flash monitoring system & 0.3624 \\
\hline ER visits, PPPY: SMBG & 0.6134 \\
\hline Cost of ER visits, PPPY: flash monitoring system & £53.64 \\
\hline Cost of ER visits, PPPY: SMBG & £90.78 \\
\hline Cost per ambulance call-out, UK NHS reference for 2016-201735 a & £248.00 \\
\hline Ambulance call-outs, PPPY: flash monitoring system & 0.1744 \\
\hline Ambulance call-outs, PPPY: SMBG & 0.5066 \\
\hline Cost of ambulance call-outs, PPPY: flash glucose monitoring system & $£ 43.25$ \\
\hline Cost of ambulance call-outs, PPPY: SMBG & £125.64 \\
\hline Cost per hospital admission, UK NHS reference for 2016-201735 a & $£ 1,590.00$ \\
\hline Hospital admissions, PPPY: flash monitoring system & 0.1208 \\
\hline Hospital admissions, PPPY: SMBG & 0.5334 \\
\hline Cost of hospital admissions, PPPY: flash glucose monitoring system & $£ 192.07$ \\
\hline Cost of hospital admissions, PPPY: SMBG & £848.11 \\
\hline Estimated cost of resource use for flash monitoring system users, PPPY & $£ 288.96$ \\
\hline Estimated cost of resource use for routine SMBG users, PPPY & f1,064.53 \\
\hline Reduction in costs (flash monitoring system versus SMBG), PPPY & £775.57 \\
\hline
\end{tabular}

Note, the rate observed over the 6-month REPLACE trial treatment period was multiplied by two to obtain the annual rate. In total, patients in the REPLACE flash monitoring arm ( $n=149)$ had 27 ER visits, 13 ambulance call-outs and 9 hospital admissions over 6 months; in the SMBG arm (n=75) there were 23 ER visits, 19 ambulance call-outs and 20 hospital admissions in the same period. ${ }^{2} 2016-2017$ UK NHS reference costs for A\&E attendance were used for ER visits; costs for 'see and treat and convey' incidents were used for ambulance call-outs; and costs for non-elective inpatient care were used for hospital admissions. ER = emergency room; NHS = National Health Service; $P P P Y=$ per patient per year; SMBG = self-monitoring of blood glucose 
Figure 2: Estimated costs of glucose monitoring and all-cause healthcare resource use PPPY for people with T2DM using intensive insulin

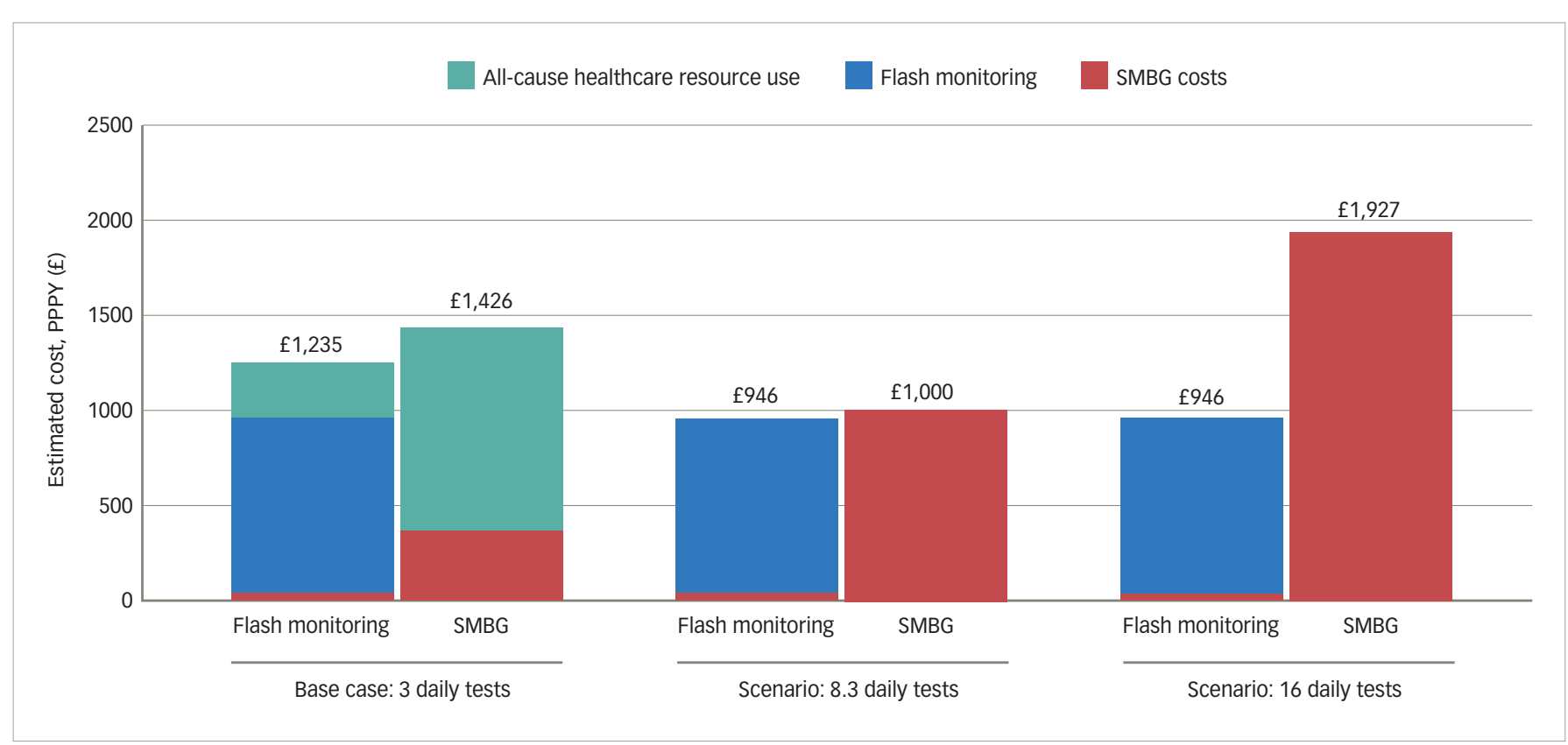

Note, resource use was excluded from the SMBG frequency scenario analyses. PPPY = per patient per year; SMBG = self-monitoring of blood glucose; T2DM = type 2 diabetes mellitus.

unable to use SMBG as often as required to maintain glycaemic control. The REPLACE study included patients of this type and demonstrated that those using the flash monitoring system achieved a substantial increase in glucose monitoring, from a mean of 3.8 SMBG tests per day in the baseline period to 8.3 scans per day over the 6-month treatment phase of the study. ${ }^{23}$ This increase in glucose monitoring was accompanied by a substantial reduction in hypoglycaemia, decreased glucose variability, and improved quality of life compared with the patients using routine SMBG. The patients using flash monitoring also required fewer hospitalisations, ER visits and ambulance call-outs than the patients using SMBG.

The base-case cost calculation presented here, using inputs from the REPLACE study, demonstrates that although the acquisition cost of flash monitoring is higher per patient than that of SMBG at a frequency of 3 tests per day, this additional cost may be offset by decreases in all-cause resource use (hospital admissions, ambulance call-outs and ER visits). Flash monitoring is potentially cost-saving once resource utilisation is considered.

Because there is no incremental cost associated with additional scanning using the flash monitoring system, at higher rates of testing the calculation becomes more favourable for flash monitoring on a basis of acquisition cost alone. The scenarios show that flash monitoring is cost-neutral compared with 8.3 SMBG tests per day, whereas for patients needing to test more than 8.3 times per day, flash monitoring is cost-saving. This is important because during real-world use of flash monitoring, many patients have been observed to scan in excess of eight times per day, ${ }^{40}$ although the real-world database does not distinguish between patients with T2DM and those with T1DM.

The scenarios overlook possible cost savings from reductions in resource use that are plausible with flash monitoring even compared with SMBG at high rates of testing. This is because the flash monitoring system can provide additional information to the patient and healthcare provider when compared with a single glucose value provided by SMBG, such as a summary ambulatory glucose profile ${ }^{41-43}$ and a complete 24-hour glucose record.

Possible limitations of this cost calculation include using all-cause resource use rather than diabetes-specific resource use, the exclusion of the cost of insulin, the variation in SMBG test strip prices and the focus on direct costs to the healthcare system.

All-cause healthcare resource use is used in economic evaluations when disease-specific resource use is difficult to assess objectively, which is the case here for an older population with a high rate of comorbidities. ${ }^{37-39} \mathrm{~A}$ recent US database study noted that distinguishing between claims that are related or unrelated to T2DM is unnecessary, given that the presence of T2DM increases the likelihood of developing other disorders that consume resources including cardiovascular and renal disease. ${ }^{36}$

Although the cost of insulin is an important consideration for people with poorly controlled T2DM, it was not included in the calculations here because the REPLACE trial showed that insulin use was similar in the flash monitoring and SMBG arms. ${ }^{34}$

The cost to the payer of SMBG is affected by the acquisition cost of test strips, which can vary between manufacturers. In this calculation, test strip costs are based on weighted average UK prices from real-world prescription data: hence, they are considered representative. Test strip prices can also vary from country to country. In cases where test strip prices are higher than in the UK, the flash monitoring system may be budget neutral at a lower glucose testing frequency than estimated in these calculations.

This cost calculation is restricted to direct treatment costs, and does not include the wider costs of T2DM managed with intensive insulin. These include the possible costs, clinical consequences and productivity 
losses associated with non-severe hypoglycaemic events. Loss of productivity in particular can be a substantial burden for people with T2DM using intensive insulin, many of whom are of working age, and for their caregivers. ${ }^{10}$ Given the substantial reduction in hypoglycaemia observed in the REPLACE trial, it is possible that flash monitoring may also reduce the indirect costs in this population.

In addition to these considerations, it is possible the reduction in hypoglycaemia observed in the REPLACE trial in favour of flash monitoring ${ }^{23}$ may lead to longer-term reductions in cardiovascular disease. ${ }^{44,45}$ Potentially, this could reduce the overall costs of the flash monitoring system over the longer term.

\section{Conclusion}

Based on UK NHS costs, the flash glucose monitoring system is affordable compared with SMBG in patients with poorly controlled T2DM using intensive insulin. In this population, flash monitoring is associated with changes in behaviour leading to increased testing frequency. Reductions in healthcare resource and long-term hypoglycaemia-related complications may make the flash monitoring system a cost-effective option. $\square$
1. National Diabetes Audit, 2016-17. Report 1: care processes and treatment targets. England and Wales. 2018. Available at: https:// digital.nhs.uk/data-and-information/publications/statistical/ national-diabetes-audit/national-diabetes-audit-report-1-care processes-and-treatment-targets-2016-17 (accessed 1 June 2018)

2. The Diabetes Control and Complications Trial Research Group. The effect of intensive treatment of diabetes on the development and progression of long-term complication in insulin-dependent diabetes mellitus. N Eng/ I Med. 1993;329:977-86

3. UK Hypoglycaemia Study Group. Risk of hypoglycaemia in types 1 and 2 diabetes: effects of treatment modalities and their duration. Diabetologia. 2007;50:1140-7.

4. Edridge $\mathrm{CL}$, Dunkley AJ, Bodicoat $\mathrm{DH}$, et al. Prevalence and incidence of hypoglycaemia in 532,542 people with type 2 diabetes on oral therapies and insulin: a systematic review and meta-analysis of population based studies. PLOS One. 2015:10:e0126427.

5. Gerstein $\mathrm{HC}$, Miller ME, Ismail-Beigi F, et al. Effects of intensive glycaemic control on ischaemic heart disease: analysis of glycaemic control on ischaemic heart disease: analysis of 2014;384:1936-41.

6. World Health Organization. Global Report on Diabetes. Available at: apps.who.int/iris/bitstream/10665/204871/1/9789241565257 eng.pdf (accessed 3 April 2017)

7. International Diabetes Foundation. IDF Diabetes Atlas, 7 th edn Brussels, Belgium: International Diabetes Federation, 2015 Available at: www.idf.org/e-library/epidemiology-research/ diabetes-atlas/13-diabetes-atlas-seventh-edition.html (accessed 1 May 2018).

8. International Diabetes Foundation. IDF Diabetes Atlas, 8th edn. Brussels, Belgium: International Diabetes Federation, 2017. Available at: www.diabetesatlas.org (Accessed 1 February 2018)

9. American Diabetes Association. Fast facts, data and statistics about diabetes, August 2017. Available at: https://professional. diabetes.org/sites/professional.diabetes.org/files/media/ diabetes.org/sites/professional.diabetes.org/files/medic

10. HexN, Bartlett C, Wright D, et al. Estimating the current and future costs of type 1 and type 2 diabetes in the UK, including direct health costs and indirect societal and productivity costs. Diabet Med. 2012;29:855-62.

11. Ulrich $\mathrm{S}$, Holle R, Wacker M, et al. Cost burden of type 2 diabetes in Germany: results from the population-based KORA studies. BMJ Open. 2016;6:e012527.

12. Tunceli $\mathrm{K}$, Holbrook T, Williams J, et al. Direct medical costs of severe hypoglycaemic events amongst type 2 diabetes patien in the UK: a retrospective database study. Presented at the European Association for the Study of Diabetes Congress, Stockholm, September 2015.

13. Zhu H, Zhu Y, Leung SW. Is self-monitoring of blood glucose effective in improving glycaemic control in type 2 diabetes without insulin treatment: a meta-analysis of randomised controlled trials. BMJ Open. 2016;6:e010524.
14. Standards of medical care in diabetes - 2017: summary of revisions. Diabetes Care. 2017;40:S4-S5

15. National Institute for Health and Care Excellence. Type 2 diabetes in adults: management. 2017. Available at: www.nice.org.uk/guidance/ng28 (accessed 2 August 2018).

16. American Diabetes Association. Standards of medical care in diabetes - 2018. Diabetes Care. 2018;41

17. Schnell $\mathrm{O}$ Alawi $\mathrm{H}$, Battelino T, et al. Consensus statement on self-monitoring of blood glucose in diabetes. Diabetes Stoffwechsel und Herz. 2009;18:3-7.

18. Lee WC, Smith E, Chubb B, Wolden ML. Frequency of blood glucose testing among insulin-treated diabetes mellitus patients in the United Kingdom. J Med Econ. 2014;17:167-75.

19. Yeaw J, Lee WC, Aagren M, Christensen T. Cost of self-monitoring of blood glucose in the United States among patients on an insulin regimen for diabetes. J Manag Care Pharm. 2012;18:21-32.

20. Yeaw J, Lee WC, Wolden ML, et al. Cost of self-monitoring of blood glucose in Canada among patients on an insulin regimen for diabetes. Diabetes Ther. 2012:3:7.

21. Elgart JF, Gonzalez L, Rucci E, Gagliardino JJ. Self-monitoring of blood glucose: use, frequency drivers, and cost in Argentina. I Diabetes Sci Technol 2014:8:1121-5.

22. Mast O, Tan A, Zweyer S, Perridy D. Usage of self-monitoring of blood glucose (SMBG) by diabetes therapy type in larger cities China. Value Health. 2012;15:A627.

23. Haak T, Hanaire H, Ajjan R, et al. Flash glucose-sensing technology as a replacement for blood glucose monitorin for the management of insulin-treated type 2 diabetes: a multicenter, open-label randomized controlled trial. Diabetes Ther. 2017;8:55-73.

24. Ong WM, Chua SS, Ng CJ. Barriers and facilitators to selfmonitoring of blood glucose in people with type 2 diabetes using insulin: a qualitative study. Patient Prefer Adheretes. 2014;8:237-46.

25. Hellmund R, Mitchell CR. Self-assessment of glucose levels in the real world is less frequent than is proposed in major guidelines. Presented at the 75th Scientific Sessions of the American Diabetes Association, 5-9 June, 2015, Boston, Massachusetts.

26. Karter AJ, Ackerson LM, Darbinian JA, et al. Self-monitoring of blood glucose levels and glycemic control: the Northern California Kaiser Permanente Diabetes registry. Am J Med 2001;111:1-9.

27. Evans JMM, Newton RW, Ruta DA, et al. Frequency of blood glucose monitoring in relation to glycaemic control: observational study with diabetes database. BMJ. 1999;319:83-6.

28. Schutt M, Kern W, Krause $U$, et al. Is the frequency of selfmonitoring of blood glucose related to long-term metabolic control? Multicenter analysis including 24,500 patients from 191 centers in Germany and Austria. Exp Clin Endocrinol Diabetes. 2006:114:384-8.

29. Kalra S, Gupta Y. Ambulatory glucose profile: Flash glucose monitoring. J Pak Med Assoc. 2015;65:1360-2.
30. Twigg SM, Kazemi MR, Craig ME. Flash continuous glucose monitoring and its IMPACT to REPLACE blood glucose monitoring in the management of type 1 and type 2 diabetes. US Endocrinology. 2017;13:57-62

31. Haak $T$, Hanaire $H$, Aijan $R$, et al. Use of flash glucose-sensing technology for 12 months as a replacement for blood glucose monitoring in insulin-treated type 2 diabetes. Diabetes Ther. 2017;8:573-86.

32. UK Drug Tariff, January 2016. Available at: www.nhsbsa.nhs.uk/ pharmacies-gp-practices-and-appliance-contractors/drug-tariff (accessed 1 February 2018)

33. Abbott Diabetes Care. Data on file

34. Haak T, Hanaire H, Ajjan RA, et al. Use of novel flash glucosesensing technology to optimise glucose control in individuals with type 2 diabetes on intensive insulin therapy. Presented at the 9th International Conference on Advanced Technologies \& Treatments for Diabetes 3-6 February 2016, Milan, Italy.

35. NHS Reference Costs 2016-17. Department of Health. Available at: https://improvement.nhs.uk/resources/reference-costs/ (accessed 4 January 2018).

36. Meng J, Casciano R, Lee YC, et al. Effect of diabetes treatmentrelated attributes on costs to type 2 diabetes patients in a realworld population. J Manag Care Spec Pharm. 2017:23:446-52.

37. O'Connor CM, Whellan DJ, Lee KL, et al. Efficacy and safety of exercise training in patients with chronic heart failure: HFACTION randomized controlled trial. JAMA. 2009;301:1439-50.

38. Meyers JL, Parasuraman S, Bell KF, et al. The high-cost, type 2 diabetes mellitus patient: an analysis of managed care administrative data. Arch Public Health. 2014;72:6.

39. Gray A, Raikou M, McGuire A, et al. Cost effectiveness of an intensive blood glucose control policy in patients with type 2 diabetes: economic analysis alongside randomised controlled trial (UKPDS 41). United Kingdom Prospective Diabetes Study Group. BMJ. 2000;320:1373-8.

40. Dunn TC, Xu Y, Hayter G, Aijan RA. Real-world flash glucose monitoring patterns and associations between self-monitoring frequency and glycaemic measures: A European analysis of over 60 million glucose tests. Diabetes Res Clin Pract. 2017:137:37-46.

41. Matthaei S. Assessing the value of the ambulatory glucose profile in clinical practice. Br J Diabetes Vasc Dis. 2014;14:148.

42. Matthaei S, DeAlaiz RA, Bosi E, et al. Consensus recommendations for the use of ambulatory glucose profile in clinical practice. Br J Diabetes Vasc Dis. 2014;14:153.

43. Bergenstal RM, Ahmann AJ, Bailey T, et al. Recommendations for standardizing glucose reporting and analysis to optimize clinical decision making in diabetes: the ambulatory glucose profile. J Diabetes Sci Technol. 2013;7:562-78.

44. Zoungas S, Patel A, Chalmers J, et al. Severe hypoglycemia and risks of vascular events and death. N Eng/ I Med. 2010;363:1410-8

45. Fonseca V, Chou E, Chung HW, Gerrits C. Economic burden of hypoglycemia with basal insulin in type 2 diabetes. Am J Manag Care. 2017;23:114-22. 